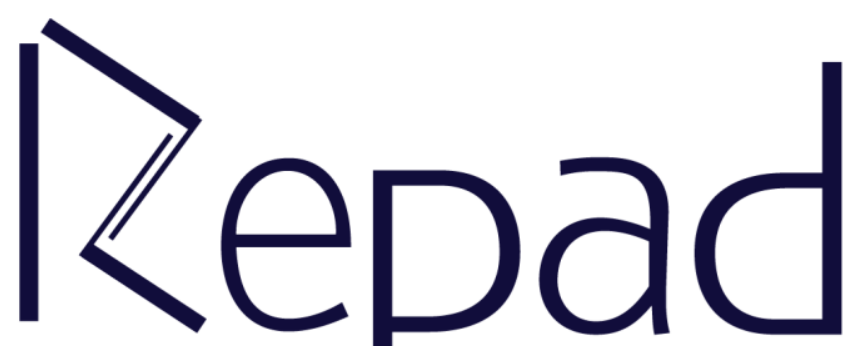

v. 4, n. 2, Maio-Agosto/2020

Revista Estudos e

Pesquisas em Administração 


\title{
PERCEPÇÃO DE QUALIDADE EM GESTÃO DE PROJETOS DE OBRAS CIVIS
}

\author{
Douglas Renan Fachinelli Moretti \\ douglas-moretti@bol.com.br \\ http $/ /$ orcid.org/0000-0003-1021-91725 \\ Universidade de São Paulo \\ São Paulo - São Paulo, Brasil \\ Jairo Cardoso Oliveira \\ http://orcid.org/0000-0001-5639-9725 \\ Universidade Nove de Julho \\ São Paulo - São Paulo, Brasil
}

\section{Resumo}

As empresas de Construção Civil estão utilizando com maior frequência as estruturas organizacionais de gerenciamento de projetos $\mathrm{e}$ as ferramentas de planejamento, monitoramento e controle com o objetivo de obter melhores índices de sucesso e qualidade nas suas obras. Nem sempre os resultados são visíveis e menos frequentemente são analisados pela perspectiva do cliente. Este trabalho se propôs a abordar se a utilização de processos e ferramentas de monitoramento e controle exerce influência na percepção de qualidade na perspectiva dos clientes. A avaliação da qualidade percebida foi feita utilizando o método Servqual em um estudo de caso comparativo em duas obras civis de até $5.000 \mathrm{~m}^{2}$, realizadas para dois clientes diferentes de uma construtora estabelecida no interior de São Paulo. No estudo de caso, um projeto fez uso de processos e ferramentas de monitoramento e controle enquanto o outro foi realizado sem utilizar esses processos. Os resultados demonstraram uma melhora na percepção de qualidade na obra que utilizou essas ferramentas. A aplicação das mesmas demonstrou maior facilidade no entendimento, melhora na confiabilidade e respostas imediatas, por parte do cliente.

Palavras-chave: Qualidade; Servqual; Cliente.

\section{PERCEPTION OF QUALITY IN PROJECT MANAGEMENT OF CIVIL WORKS}

\begin{abstract}
Civil Construction companies are using the organizational structures of project management and planning, monitoring and control tools more frequently in order to obtain better success rates and quality in their works. Results are not always visible and are less often analyzed from the customer's perspective. This work aimed to address whether the use of monitoring and control processes and tools have an influence on the perception of quality from the customers' perspective. The perceived quality assessment was carried out using the Servqual method in a comparative case study in two civil works of up to $5,000 \mathrm{~m} 2$, carried out for two different clients of a construction company established in the interior of São Paulo. In the case study, one project made use of monitoring and control processes and tools while the other was carried out without using these processes. The results showed an improvement in the perception of quality
\end{abstract}


in the work that used these tools. Their application demonstrated greater ease of understanding, improved reliability and immediate responses by the customer.

Keywords: Quality; Servqual; Customer.

Submetido: 30/11/2019

Nova Submissão: 26/01/2020

Aceito: $15 / 04 / 2020$

Publicado: 31/05/2020

\section{Introdução}

A arte de planejar é uma ferramenta de gerenciamento primordial para os processos, objetivos e metas das empresas da atualidade. Planejar compõe-se de estruturar um plano, por intermédio de ferramentas, para lapidar o alcance de um determinado objetivo (PMI, 2013). O planejamento e o controle são pilares fundamentais para alcançar as entregas com alto nível de qualidade.

Gerentes de projetos se encontram em cenários cada vez mais exigentes e competitivos, nos quais existe grande expectativa na entrega de projetos e soluções de forma rápida, precisa, segura e com grande qualidade, mas cujos prazos e custos planejados, se tornam cada vez mais limitados. A gestão de projetos desempenha um papel de grande importância para as empresas alcançarem seus objetivos estratégicos (DINSMORE; COOKIE-DAVIS, 2006).

A gestão da qualidade é uma área de grande importância também no universo do gerenciamento dos projetos, uma vez que se encarrega de garantir a satisfação do cliente por intermédio do cumprimento de todos os requisitos. Segundo Kerzner (2009), nas últimas décadas houve uma verdadeira revolução em qualidade, com os clientes demandando requisitos de maior desempenho, desenvolvimento de produtos mais rápidos, maiores níveis de tecnologia, materiais e processos estendidos até o limite, menor número de rejeições e defeitos. Segundo o guia PMBOK (PMI, 2013), um guia de boas práticas mais aceito na comunidade da gestão de projetos, o gerenciamento da qualidade é estruturado com base em três processos principais, que inclui aqueles necessários para assegurar que o projeto satisfaça as necessidades para as quais foi criado. Esses três processos são compostos pelo planejamento da qualidade (identificar), garantia da qualidade (avaliar o desempenho), e controle da qualidade (controlar resultados).

A área de construção civil tem uma representatividade relevante na atividade econômica do país, com consequentes efeitos na empregabilidade (AZEVEDO et al., 2011). A construção civil é intensiva em utilização de conceitos de gestão de projetos, sendo uma das primeiras áreas em que foram utilizados conceitos de gestão de projetos no Brasil (CODAS, 1987).

O objetivo deste trabalho foi analisar a percepção da qualidade dos entregáveis em obra de Engenharia Civil comparando os resultados de uma pesquisa realizada com clientes de duas obras, chamadas de A e B com porte similar, sendo que em uma delas foram utilizadas ferramentas de planejamento, monitoramento, controle e na outra não houve essa utilização. Por meio do modelo de percepção da qualidade, Servqual, foram embasadas as perguntas da pesquisa para obter resultados comparativos com relação às dimensões da escala Servqual (aspectos tangíveis, confiabilidade, resposta, garantia e 
empatia). Assim, este artigo responde a seguinte questão de pesquisa: A utilização de ferramentas de monitoramento e controle tem influência na percepção de qualidade na entrega de uma obra de até $5000 \mathrm{~m}^{2}$ ?

\section{Referencial Teórico}

Maximiano (2010) aponta que construir uma estrutura de concreto para servir de residência, escritório ou fábrica, desenvolver uma estação espacial e colocá-la na órbita da Terra, estruturar e realizar um grande evento, mobilizando milhões de pessoas ao redor do mundo, como a copa do mundo e os Jogos Olímpicos são todos conjuntos de empreendimentos que possuem dois aspectos fundamentais: são todos concretos e podem ser gerenciados como projetos.

Projeto, segundo o guia PMBOK (PMI, 2013), é um esforço ou evento que tem início e fim bem definidos no tempo, um escopo, com um esforço empreendido para criar um produto, serviço ou resultado com entregáveis específicos, únicos. Difere de uma operação, em que muitas vezes apresentam tarefas diárias, e não se sabe quando ela será ou não mais necessária, tratando-se de algo rotineiro (PMI, 2013).

Com a evolução dos mecanismos e a necessidade de processos otimizados nos canteiros, tornou-se imprescindível o gerenciamento total dos recursos empregados em uma obra, seja ela de grande ou pequeno porte, visando aperfeiçoar todos os processos, melhorarem a qualidade e reduzir os recursos financeiros aplicados (BORGES, 2013).

O setor da construção civil tem procurado adaptar conceitos, métodos e técnicas desenvolvidas para ambientes de produção industrial criando assim estruturas específicas para os ambientes das obras. A intenção destas estruturas é propor para os profissionais da gestão da construção civil uma solução atendendo as expectativas na concepção do projeto e na execução da obra nos aspectos de viabilidade econômica do projeto, gerenciamento do projeto, análise de investimento e planejamento das atividades, com o objetivo de tornar a obra um negócio rentável, com custos e prazos mais sólidos (BORGES, 2013).

\subsection{Gerenciamento de projetos}

Os projetos vêm sendo executados desde os primórdios da civilização, como a construção das pirâmides do Egito, a Grande Muralha da China, a Torre Eiffel, entre outras construções que persistem até os dias de hoje. Pode-se dizer que para execução destes projetos eram aplicados algum conceito de planejamento, organização e controle. Pensar em gerenciamento de projetos, portanto, não é algo novo como conhecimento, sendo que indivíduos de várias épocas e culturas diferentes vêm criando novos produtos e serviços introduzindo mudanças e inovações no processo da história da civilização (MAXIMIANO, 2010).

Apenas na segunda metade do século XX o gerenciamento de projetos se estabeleceu em função da complexidade dos projetos e dos produtos esperados, tornando-se necessário criar conceitos, estruturas e ferramentas de gerenciamento para atender o surgimento de computadores, o fim da segunda guerra mundial com a reconstrução da Europa e a exploração espacial. Na década de 1960 surgiu o Project Management Institute (PMI), o qual reuniu e organizou as melhores práticas voltadas para o gerenciamento de projetos, transformando a estrutura em tópicos e disciplinas elencadas no corpo de conhecimento Project Management Body of Knowledge PMBOK (MAXIMIANO, 2010). 
O gerenciamento de projetos é a aplicação de conhecimentos, habilidades, ferramentas de planejamento e técnicas para a execução de projetos de forma efetiva e eficaz. Gerenciar projetos requer aptidões e domínio de processos específicos que aplicados em conjunto geraram como forma de entregáveis produtos e serviços exclusivos em um determinado período de tempo (PMI, 2013).

Este gerenciamento é um conjunto de modelos e técnicas para o desempenho eficiente dos projetos individuais considerando cada projeto como uma empreitada isolada. A abordagem possui um tamanho único que se encaixa para cada tipo de escopo, não leva em conta a natureza ou contexto em que são realizados.

\subsection{Ferramentas de monitorame nto e controle}

$\mathrm{O}$ guia PMBOK oferece tópicos, processos e ferramentas para auxiliar no processo de iniciação dos projetos, planejamento para atender ao escopo estabelecido e para a execução do projeto (PMI, 2013).

Este trabalho chama atenção para as ferramentas de monitoramento e controle com foco principal no controle do Tempo, controle do Custo e Gestão da qualidade percebida, por meio das ferramentas da gestão e de indicadores de tempo e custo com a aplicação do modelo de percepção da qualidade, chamado Servqual, o qual será explorado nos tópicos seguintes.

Este grupo de ferramentas, apresentado pelo PMBOK (PMI, 2013), envolve o monitoramento dos resultados para garantir que estejam de acordo com o planejado, porém o foco principal é providenciar meios para manter ou retornar os processos que estão sendo executados para o caminho certo, identificando onde e como é preciso atuar para manter o planejado e atingir o entregável final mantendo os prazos e custos estabelecidos no planejamento inicial do projeto (BATEMAN; SNELL, 1998). É possível resumir em três tópicos a finalidade destas ferramentas:

- Verificar se a ação planejada está efetivamente sendo executada e se os resultados dessa ação correspondem ao desempenho desejado.

- Assegurar que os objetivos sejam alcançados.

- Verificar se é necessário modificar a ação ou o objetivo.

O processo de monitoramento e controle produz informações sobre diversas variáveis do desempenho do projeto, tais como, escopo, custos, riscos, recursos humanos e assim por diante (MAXIMIANO, 2010).

De acordo com o guia PMBOK (PMI, 2013), os processos de monitorar e controlar são subdivididos de acordo com os seguintes tópicos:

- Monitorar e controlar o trabalho do projeto.

- Realizar o controle integrado das mudanças.

- Validar o escopo.

- Controlar o escopo.

- Controlar o cronograma.

- Controlar os custos.

- Controlar a qualidade.

- Controlar as comunicações.

- Controlar os riscos.

- Controlar as aquisições.

- Controlar o envolvimento das partes interessadas. 
Tempo, o controle deste tópico focaliza a duração prevista do projeto, as datas importantes previstas para início e conclusão de fases e as datas previstas para entrega dos produtos (MAXIMIANO, 2010).

- As datas planejadas estão sendo respeitadas; o projeto está acompanhando o cronograma, está atrasado ou adiantado?

- Faz-se necessário replanejar o cronograma?

Custo, o controle focaliza a duração planejada e prevista para o projeto, o cronograma de desembolsos previstos e o cronograma de liberação de recursos necessário para atender as sequências do projeto (MAXIMIANO, 2010).

- A quantidade de consumo de recursos corresponde ao previsto?

- O projeto precisará de mais ou menos recursos do que o previsto?

- Quais ações devem ser tomadas, a partir deste ponto, para assegurar que o projeto alcance o resultado?

Sucesso em projetos pode ser definido a partir do atendimento de três parâmetros principais, o atendimento dos requisitos de qualidade, do atingimento do tempo e custos definidos para o projeto. Um produto ou serviço deve manter a qualidade atendendo ao escopo ou necessidades implícitas e explícitas do cliente, atender ao tempo estabelecido disponibilizado e cronograma, e manter os custos planejados (PMI, 2013). Esses três parâmetros são definidos por Atkinson (1999) como o triângulo de ferro, como apresentado na Figura 1.

Figura 1. Triângulo da restrição tripla

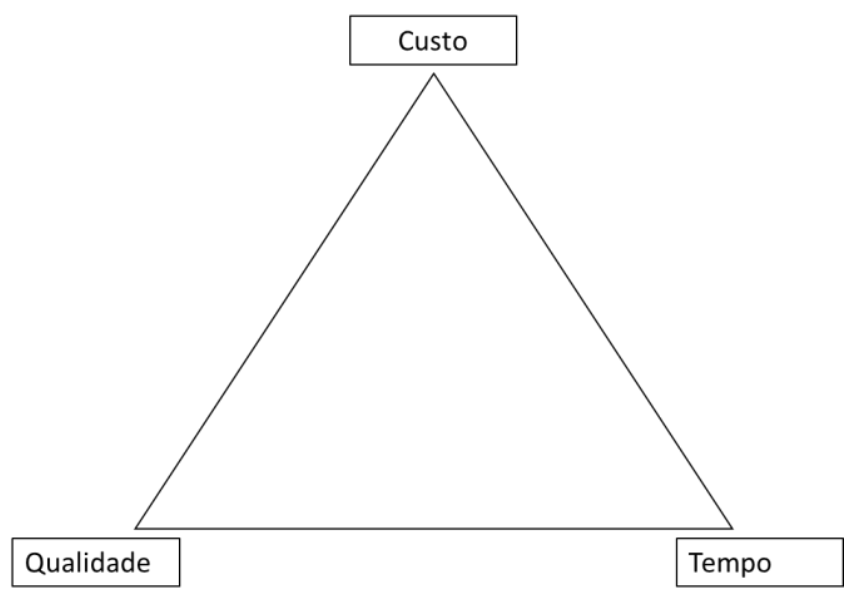

Fonte. Atkinson (1999)

O triângulo de ferro, também chamado de triângulo da tripla restrição, deve apresentar um equilibrio e com isso limita as alterações em cada uma das áreas. A qualidade é apresentada como item relevante, pois deve ser mantida mesmo que as demais áreas sofram alterações durante o tempo de vida do projeto. O triângulo da restrição indica que para aumentar escopo, é necessário aumentar o custo e/ou o prazo; para diminuir o prazo, é necessário aumentar o custo e/ou reduzir o escopo; para diminuir o custo, é necessário reduzir o escopo (ATKINSON, 1999). 


\subsection{Gestão da Qualidade}

A garantia da qualidade não elimina a necessidade do controle da qualidade, que continua a ser um dos elementos do sistema da qualidade. No entanto, a eficiência do sistema de garantia da qualidade muda a ênfase do controle. A ênfase, no processo de controle, está em encontrar os erros. Nos sistemas modernos de administração da qualidade, a ênfase está em assegurar que o resultado correto seja obtido (MAXIMIANO, 2010).

A gestão da qualidade de um serviço ou produto começa com a definição de especificações como requisitos que convertem as necessidades e interesses dos clientes em desempenho esperado. As especificações de desempenho devem rejeitar as características indesejadas ou desnecessárias e incorporar as características desejadas pelos clientes (MAXIAMIANO, 2010). Carvalho e Rabechini Jr. (2015) apontam que a gestão da qualidade deve buscar a produção mais genial, que esteja dentro do possível, considerando as restrições de recursos e prazos do projeto.

Segundo Kerzner (2009), muitas empresas falham quando tentam determinar o que é qualidade. A razão desta falha, segundo o autor, está ligada ao conceito que a qualidade é definida pelo cliente. Ainda, segundo Kerzner (2009), além de ser definida pelo cliente, a qualidade também deve considerar a ligação com a lucratividade tanto no mercado quanto nos custos e deve ser parte integrante do plano estratégico da empresa. De acordo com o PMBOK (PMI, 2013), a qualidade é uma área de conhecimento organizada em três processos sendo planejamento, garantia e controle onde são determinados o plano de gerenciamento da qualidade, a execução da garantia da qualidade e o controle da qualidade.

Este trabalho utiliza a ferramenta desenvolvida para avaliar a percepção dos clientes sobre a qualidade de um serviço, o modelo de pesquisa chamado Servqual. Essa ferramenta é considerada um dos principais resultados da pesquisa feita pelos cientistas Parasuraman, Zeithaml e Berry do "Marketing Science Institute", localizado em Cambridge - Massachusetts (Estados Unidos) - sobre qualidade em serviços (BERRY; PARASURAMAN, 1995).

Os resultados da aplicação desta ferramenta Servqual, possuem dois pontos fortes, sendo o alerta para que sejam consideradas as percepções de ambas as partes, profissionais de marketing e consumidores, no processo de intercâmbio, e ao abordar as diferenças para servir como base lógica para a formulação de estratégia garantindo a coerência entre experiências e expectativas. A pesquisa alcançou a conclusão de que a qualidade de serviço é percebida pelos clientes como o tamanho da discrepância entre suas expectativas ou desejos e suas efetivas percepções. $\mathrm{O}$ maior conhecimento obtido foi a constatação de que o consumidor fazia o uso de critérios em sua essência semelhantes na avaliação da qualidade, mesmo para serviços de natureza distinta, o que resultou em um agrupamento em cinco dimensões principais da qualidade, conforme abaixo (BERRY; PARASURAMAN, 1995).

- Tangibilidade: qual a aparência das instalações físicas, equipamentos, pessoal e materiais de comunicação.

- Confiabilidade: qual a capacidade de executar o serviço prometido de forma confiável e com precisão.

- Resposta: qual a disposição da equipe para ajudar os clientes e prestar um serviço rápido.

- Garantia: qual o conhecimento e cortesia dos funcionários e sua capacidade de transmitir confiança e segurança. 
- Empatia: qual o cuidado e atenção individualizada que a empresa fornece aos seus clientes.

O Servqual mede a qualidade do serviço baseando-se nas expectativas do cliente em contraponto com a percepção que esse mesmo cliente tem em relação ao serviço que recebeu. A metodologia busca saber quais fatores o cliente considera mais importantes na prestação de um serviço. O método consiste em duas entrevistas que devem ser realizadas com os clientes, focando em 22 perguntas preestabelecidas (BERRY; PARASURAMAN, 1995). Em ambas as entrevistas, o cliente deve atribuir uma pontuação relativa à qualidade dos serviços utilizando uma escala do tipo Likert, que possui sete pontos entre 1 (discordo totalmente) a 7 (concordo totalmente).

A primeira entrevista questiona o cliente em relação ao que ele pensa ser ideal ou mais importante para que uma empresa realize o serviço avaliado, sendo a pontuação da expectativa. Nesta entrevista também é solicitada a distribuição de 100 pontos, de peso, entre as cinco dimensões da qualidade, coletando assim o nível de importância de cada dimensão para aquele cliente (BERRY; PARASURAMAN, 1995). A segunda entrevista visa entender o que o cliente pensa sobre a qualidade de uma empresa específica, ou seja, sobre a empresa em questão, sendo a pontuação da percepção (BERRY; PARASURAMAN, 1995).

Com os resultados, utiliza-se a nota que o cliente atribuiu na segunda entrevista, percepção da empresa, e subtrai da nota que ele atribuiu ao que considerava ideal, expectativa da empresa ideal. O resultado será o nível da qualidade do serviço, valores positivos quando a empresa supera as expectativas do cliente, valores negativos quando a empresa não atinge as expectativas do cliente. Com os resultados é feita a verificação do nível de satisfação dos clientes. Para isso é verificado o resultado do nível de percepção de cada uma das cinco dimensões em relação ao limite de $80 \%$ do máximo da escala Likert. Estudos científicos demonstram que a partir de $80 \%$ temos uma zona de lealdade, pela qual progressivamente espera-se uma maior fidelização do cliente (BERRY; PARASURAMAN, 1995).

São aplicados os pesos, ou grau de importância, que o cliente atribuiu para cada uma das cinco dimensões para analisar as diferenças calculadas entre a expectativa e a percepção. Para isso é multiplicado o peso atribuído para a dimensão por cada um dos resultados de diferença de cada uma das questões, calculando assim uma diferença ponderada. Com estes resultados é calculada a média da diferença ponderada, o valor mais baixo identifica a dimensão, dentro as cinco, que tem grande problema de qualidade e dentro desta dimensão o valor mais baixo da diferença ponderada identifica a questão específica a ser melhorada para atingir a qualidade esperada pelo cliente (BERRY; PARASURAMAN, 1995).

\section{Procedimentos Metodológicos}

Com o objetivo de responder a questão de pesquisa proposta "A utilização de ferramentas de monitoramento e controle tem influência na percepção de qualidade na entrega de uma obra de até $5.000 \mathrm{~m}^{2}$ ?", este trabalho realizou pesquisas bibliográficas e buscou uma forma de avaliar a qualidade pela perspectiva do cliente, tal como indicado por Kerzner (2009). Para tanto, o modelo Servqual (BERRY; PARASURAMAN, 1995) de percepção da qualidade foi utilizado.

A pesquisa buscou embasar na literatura quais as principais características que influenciam a qualidade de uma obra para o cliente com relação às cinco dimensões 
levantadas pela análise Servqual (aspectos tangíveis, confiabilidade, resposta, garantia e empatia). O modelo Servqual foi disponibilizado para clientes de duas obras, chamadas neste estudo de obra A e obra B, com porte similar e área de até $5000 \mathrm{~m}^{2}$, sendo que a obra A utilizou ferramentas de monitoramento e controle e a obra B não utilizou.

Inicialmente foi realizada uma entrevista com o diretor de operações da construtora e os gerentes de projeto de cada uma das obras. A empresa construtora é de pequeno porte, atuando no interior do estado de São Paulo com projetos industriais de até $5.000 \mathrm{~m}^{2}$. Segundo o diretor de operações a construtora iniciou um processo de adoção das melhores práticas de gestão de projetos, tendo realizado treinamentos com base nos processos do PMBOK para seus engenheiros civis, que são os responsáveis pela evolução de suas obras (projetos). A construtora adotou uma série de boas práticas para o monitoramento de suas obras, incluindo a comparação sistemática do cronograma com sua linha de base, elaborando gráficos de controle que serão apresentados no decorrer deste artigo.

Desta forma, foi possível detectar desvios na condução temporal dos projetos e adotar ações de mitigação. Outra boa prática empregada foi a utilização da técnica de gestão de valor agregado (também conhecida como earned value management - EVM), com a qual as previsões de custos a incorrer permitem atuar preventivamente para evitar custos não devidos. A segunda parte das entrevistas ocorreu com os clientes de dois projetos de porte semelhante, sendo que a construtora disponibilizou os contatos dos clientes, bem como disponibilizou os dados da evolução dos projetos e acesso aos gerentes dos projetos das Obras A e B.

O projeto denominado Obra A teve como escopo a construção de um galpão industrial com $4.500 \mathrm{~m}^{2}$. Este galpão teve o objetivo de atuar como um posto de transbordo de cargas para uma empresa que atua como transportadora no interior do Estado de São Paulo. Já o projeto B construiu também um galpão industrial, com $4.800 \mathrm{~m}^{2}$ para ser utilizado por uma empresa industrial de embalagens de papelão.

O modelo Servqual foi aplicado a estes dois clientes através de entrevista presencial com a utilização do instrumento de pesquisa do modelo. Aos clientes não foi oferecida a informação se sua obra utilizou as novas ferramentas de monitoramento e controle durante a execução do gerenciamento do projeto. Esta restrição teve a intenção de evitar o viés que pudesse tender a correlacionar a percepção de qualidade com o monitoramento e controle aplicado.

Foram consideradas as respostas apenas das pessoas ligadas diretamente com as obras citadas que puderam observar no dia a dia a evolução do projeto e o alcance dos entregáveis conforme a qualidade desejada. $\mathrm{Na}$ obra $\mathrm{A}$ foram entrevistadas 5 pessoas (diretor de logística, gerente de entreposto, dois engenheiros civis e o responsável pela manutenção da futura instalação). No projeto B, foram entrevistados 6 representantes da empresa (diretor de engenharia, gerente de produção, responsável pela manutenção elétrica, responsável pela manutenção predial e gerente de compras). Todas as entrevistas foram feitas após a conclusão técnica e financeira da obra.

\section{Análise dos Resultados e Discussão}

Os resultados são apresentados pela análise das dimensões avaliadas no modelo Servqual. O método Servqual tem como caraterística avaliar a diferença entre a percepção que o cliente tem quanto à qualidade de um serviço prestado e a expectativa 
gerada para esse serviço. Nas Tabelas numeradas de 1 a 10 as indicações estão descritas como percepção, expectativa e diferença.

\subsection{Tangibilidade}

Considerando os aspectos tangíveis para a obra A, em apenas um dos quesitos a expectativa dos entrevistados foi superada. Em outros três quesitos os resultados não atingiram o esperado pelos entrevistados. Os dados podem ser verificados na Tabela 1.

Tabela 1. Resultado análise Servqual obra A - tangibilidade

\begin{tabular}{lccc}
\hline Tangibilidade - Obra A & Percepção & Expectativa & Diferença \\
\hline Q1. Equipamentos e ferramentas de visual moderno? & 3,5 & 5,5 & $-2,0$ \\
Q2. Instalações físicas de escritórios com visual & 5,5 & 6,0 & $-0,5$ \\
atraente? & 5,8 & 5,3 & 0,5 \\
$\begin{array}{l}\text { Q3. Funcionários com aparência asseados, bem } \\
\text { apresentados? }\end{array}$ & 5,5 & 5,8 & $-0,3$ \\
$\begin{array}{l}\text { Q4. Papéis e materiais de apoio ao canteiro com bom } \\
\text { apelo visual? }\end{array}$ & & & \\
\hline
\end{tabular}

Fonte. Resultados originais da pesquisa

Para a tangibilidade, os entrevistados da obra B também responderam o mesmo questionário e em um dos quesitos foram atingidas e superadas suas expectativas. Em outros três não foi obtido o esperado, conforme resultados da Tabela 2 .

Tabe la 2. Resultado análise Servqual obra B - tangibilidade

\begin{tabular}{lccc}
\hline Tangibilidade - Obra B & Percepção & Expectativa & Diferença \\
\hline Q1. Equipamentos e ferramentas de visual moderno? & 4,2 & 5,5 & $-0,3$ \\
Q2. Instalações físicas de escritórios com visual & 3,0 & 5,5 & $-2,5$ \\
atraente? & 3,5 & 4, & $-0,5$ \\
$\begin{array}{l}\text { Q3. Funcionários com aparência asseados, bem } \\
\text { apresentados? }\end{array}$ & & & 1,5 \\
$\begin{array}{l}\text { Q4. Papéis e materiais de apoio ao canteiro com bom } \\
\text { apelo visual? }\end{array}$ & 4,5 & 3,0 & \\
\hline
\end{tabular}

Fonte. Resultados originais da pesquisa.

Com os dados obtidos foi possível estabelecer a percepção média e a taxa de satisfação para as obras.

- Obra A: para os aspectos tangíveis a percepção média alcançou o valor de 5,08, atingindo uma taxa de satisfação de $73 \%$.

- Obra B: para os aspectos tangíveis a percepção média alcançou o valor de 3,80, atingindo uma taxa de satisfação de $54 \%$.

Na obra A, verificou-se uma taxa de satisfação $11 \%$ maior do que na obra $\mathrm{B}$, demonstrando assim uma percepção maior do cliente com o aspecto da aparência das instalações físicas, equipamentos, pessoal e materiais de comunicação.

\subsection{Confiabilidade}

Considerando os quesitos da dimensão confiabilidade, a obra $\mathrm{A}$ atingiu e superou as expectativas dos entrevistados, sendo que somente em um dos quesitos não foram atingidos os patamares desejados. Os resultados estão na Tabela 3. A 
confiabilidade para a obra B não atingiu as expectativas dos entrevistados em nenhum dos quesitos, conforme resultados e itens da Tabela 4.

Com os dados obtidos foi possível estabelecer a percepção média e a taxa de satisfação para as obras.

- Obra A: para a confiabilidade a percepção média alcançou o valor de 5,90, atingindo uma taxa de satisfação de $84 \%$.

- Obra B: para a confiabilidade a percepção média alcançou o valor de 3,40, atingindo uma taxa de satisfação de $49 \%$.

Tabela 3. Resultado análise Servqual obra A - confiabilidade

\begin{tabular}{lccc}
\hline Confiabilidade - Obra A & Percepção & Expectativa & Diferença \\
\hline Q5. A equipe realiza promessas no prazo acordado? & 5,5 & 4,7 & 0,8 \\
Q6. Existe o interesse sincero na solução dos & 6,5 & 5,3 & 1,2 \\
problemas? & & & \\
Q7. Os serviços programados foram realizados certos & 6,2 & 5,5 & 0,7 \\
da primeira vez? & & & \\
Q8. Foram realizados os serviços no prazo acertado? & 5,5 & 6,0 & $-0,5$ \\
Q9. Foi registrado serviços sem erros? & 5,8 & 5,0 & 0,8 \\
\hline
\end{tabular}

Fonte. Resultados originais da pesquisa

Tabela 4. Resultado análise Servqual obra B - confiabilidade

\begin{tabular}{lccc}
\hline Confiabilidade - Obra B & Percepção & Expectativa & Diferença \\
\hline Q5. A equipe realiza promessas no prazo acordado? & 3,5 & 5,5 & $-2,0$ \\
Q6. Existe o interesse sincero na solução dos & 4,5 & 6,0 & $-1,5$ \\
problemas? & & & \\
Q7. Os serviços programados foram realizados certos & 3,0 & 5,5 & $-2,5$ \\
da primeira vez? & & & \\
Q8. Foram realizados os serviços no prazo acertado? & 2,0 & 6,0 & $-4,0$ \\
Q9. Foi registrado serviços sem erros? & 4,0 & 5,5 & $-1,5$ \\
\hline
\end{tabular}

Fonte. Resultados originais da pesquisa

Na obra A, verificou-se uma taxa de satisfação $35 \%$ maior do que a obra $\mathrm{B}$, possibilitando demonstrar, segundo a percepção de qualidade do cliente, a importância de uma capacidade maior de executar o serviço prometido de forma confiável e com precisão. A obra $\mathrm{B}$ atingiu uma baixa taxa de satisfação, verificou-se que não alcançou em nenhum dos quesitos o que o cliente tinha de expectativa. A percepção deste cliente com relação ao serviço prometido foi abaixo do esperado devido a não ter sido cumprido os prazos acordados em cronograma.

\subsection{Resposta}

Para a dimensão resposta a obra $\mathrm{A}$ em todos os quesitos foram alcançadas e superadas expectativas dos entrevistados, conforme resultados da Tabela 5. 
Tabela 5. Resultado análise Servqual obra A - resposta

\begin{tabular}{lccc}
\hline Resposta - Obra A & Percepção & Expectativa & Diferença \\
\hline $\begin{array}{l}\text { Q10. Os funcionários informam exatamente quando o } \\
\text { serviço será prestado? }\end{array}$ & 5,8 & 5,3 & 0,5 \\
$\begin{array}{l}\text { Q11. Os funcionários entregam serviços } \\
\text { prontamente? }\end{array}$ & 6,0 & 5,8 & 0,2 \\
$\begin{array}{l}\text { Q12. Os funcionários sempre estão dispostos a } \\
\text { ajudar? }\end{array}$ & 5,5 & 4,0 & 1,5 \\
$\begin{array}{l}\text { Q13. Os funcionários nunca estão ocupados demais } \\
\text { para atender pedidos? }\end{array}$ & 4,0 & 3,5 & 0,5 \\
\hline
\end{tabular}

Fonte. Resultados originais da pesquisa

Para a dimensão resposta na obra $\mathrm{B}$, verificou-se que em todos os quesitos não foram atingidas as expectativas dos entrevistados, apresentados conforme Tabela 6.

Tabela 6. Resultado análise Servqual obra B - resposta

\begin{tabular}{|c|c|c|c|}
\hline Resposta - Obra B & Percepção & Expectativa & Diferença \\
\hline $\begin{array}{l}\text { Q10. Os funcionários informam exatamente quando o } \\
\text { serviço será prestado? }\end{array}$ & 5,0 & 5,8 & $-0,8$ \\
\hline $\begin{array}{l}\text { Q11. Os funcionários entregam serviços } \\
\text { prontamente? }\end{array}$ & 4,0 & 5,5 & $-1,5$ \\
\hline $\begin{array}{l}\text { Q12. Os funcionários sempre estão dispostos a } \\
\text { ajudar? }\end{array}$ & 4,5 & 5,0 & $-0,5$ \\
\hline $\begin{array}{l}\text { Q13. Os funcionários nunca estão ocupados demais } \\
\text { para atender pedidos? }\end{array}$ & 3,0 & 4,5 & $-1,5$ \\
\hline
\end{tabular}

Fonte. Resultados originais da pesquisa

Com os dados obtidos foi possível estabelecer a percepção média e a taxa de satisfação para as obras.

- Obra A: para a resposta a percepção média alcançou o valor de 5,33, atingindo uma taxa de satisfação de $76 \%$.

- Obra B: para a resposta a percepção média alcançou o valor de 4,13, atingindo uma taxa de satisfação de $59 \%$.

$\mathrm{Na}$ obra A, verificou-se uma taxa de satisfação $17 \%$ maior do que a obra B. Com esta avaliação, o cliente sinaliza a disposição maior da equipe para ajudar os clientes e prestar um serviço rápido.

Para esta dimensão foi possível fornecer claramente a resposta pelos colaboradores utilizando ferramentas que auxiliam e monitoram os resultados para garantir que estejam de acordo com o planejado, trazendo assim informações mais objetivas e corretas para os clientes. De acordo com Bateman e Snell (1998), o foco principal em monitorar e controlar é providenciar meios para manter ou retornar os processos que estão sendo executados para o caminho certo, identificando onde e como é preciso atuar para manter o planejado.

\subsection{Garantia}

Para a dimensão garantia, a obra $\mathrm{A}$ em dois quesitos atingiu e superou as expectativas dos entrevistados. Entretanto, outros dois quesitos não foram atingidos conforme esperado. A Tabela 7 apresenta os detalhes. 
Tabela 7. Resultado análise Servqual obra A - garantia

\begin{tabular}{|c|c|c|c|}
\hline Garantia - Obra A & Percepção & Expectativa & Diferença \\
\hline $\begin{array}{l}\text { Q14. O comportamento dos funcionários inspira } \\
\text { confiança? }\end{array}$ & 5,5 & 5,8 & $-0,3$ \\
\hline $\begin{array}{l}\text { Q15. Os clientes sentem-se seguros em suas } \\
\text { transações, opções? }\end{array}$ & 3,5 & 4,7 & $-1,2$ \\
\hline $\begin{array}{l}\text { Q16. Os funcionários são consistentemente corteses } \\
\text { com os clientes? }\end{array}$ & 5,0 & 3,9 & 1,1 \\
\hline $\begin{array}{l}\text { Q17. Todos os funcionários têm conhecimento para } \\
\text { responder as questões? }\end{array}$ & 4,5 & 3,0 & 1,5 \\
\hline
\end{tabular}

Fonte. Resultados originais da pesquisa

Para a dimensão garantia, a obra B atingiu e superou as expectativas dos entrevistados em três quesitos. Somente um não alcançou o esperado. Os detalhes estão apresentados na Tabela 8.

Tabela 8. Resultado análise Servqual obra B - garantia

\begin{tabular}{lcccc}
\hline Garantia - Obra B & Percepção & Expectativa & Diferença \\
\hline $\begin{array}{l}\text { Q14. O comportamento dos funcionários inspira } \\
\text { confiança? }\end{array}$ & 6,3 & 5,5 & 0,8 \\
$\begin{array}{l}\text { Q15. Os clientes sentem-se seguros em suas } \\
\text { transações, opções? }\end{array}$ & 4,8 & 4,0 & 0,8 \\
$\begin{array}{l}\text { Q16. Os funcionários são consistentemente corteses } \\
\text { com os clientes? }\end{array}$ & 5,1 & 4,5 & 0,6 \\
$\begin{array}{l}\text { Q17. Todos os funcionários têm conhecimento para } \\
\text { responder as questões? }\end{array}$ & 3,0 & 3,5 & $-0,5$ \\
\hline
\end{tabular}

Fonte. Resultados originais da pesquisa

Com os dados levantados, foi possível estabelecer a percepção média e a taxa de satisfação para as obras.

- Obra A: para a garantia a percepção média alcançou o valor de 4,63, atingindo uma taxa de satisfação de $66 \%$.

- Obra B: para a garantia a percepção média alcançou o valor de 4,83, atingindo uma taxa de satisfação de $69 \%$.

$\mathrm{Na}$ obra B, verificou-se uma taxa de satisfação $3 \%$ maior do que a obra A. Foi verificada uma diferença em conhecimento e cortesia dos funcionários e sua capacidade de transmitir confiança e segurança. Mesmo a obra B não atingindo as expectativas dos clientes em diversos quesitos consideradas as dimensões confiabilidade e resposta, a garantia na obra B superou a percepção de qualidade do cliente com uma pequena diferença da obra A.

\subsection{Empatia}

Para os quesitos da dimensão empatia, a obra A atingiu e superou as expectativas dos entrevistados em três deles. Outros dois quesitos não atingiram a expectativa dos entrevistados, conforme pode ser verificado na Tabela 9. 
Tabela 9. Resultado análise Servqual obra A - empatia

\begin{tabular}{lccc}
\hline Empatia - Obra A & Percepção & Expectativa & Diferença \\
\hline Q18. E fornecida atenção individual aos clientes? & 4,5 & 3,9 & 0,6 \\
$\begin{array}{l}\text { Q19. O funcionamento é em horários convenientes } \\
\text { para atender a necessidade de todos os seus clientes? }\end{array}$ & 5,5 & 5,2 & 0,3 \\
$\begin{array}{l}\text { Q20. Os funcionários dão atenção pessoal aos } \\
\text { clientes? }\end{array}$ & 4,8 & 3,6 & 1,2 \\
$\begin{array}{l}\text { Q21. Os funcionários têm verdadeiramente o melhor } \\
\text { interesse nos clientes? }\end{array}$ & 4,1 & 5,5 & $-1,4$ \\
$\begin{array}{l}\text { Q22. Os funcionários entendem as reais necessidades } \\
\text { dos clientes? }\end{array}$ & 4,5 & 6,0 & $-1,5$ \\
\hline
\end{tabular}

Fonte. Resultados originais da pesquisa

Para a mesma dimensão, os resultados alcançados na obra B demonstraram o atingimento e superação das expectativas dos entrevistados em três quesitos, consequentemente dois quesitos tiveram resultados aquém das expectativas. Os resultados estão demonstrados na Tabela 10.

Tabela 10. Resultado análise Servqual obra B - empatia

\begin{tabular}{lccc}
\hline Empatia - Obra B & Percepção & Expectativa & Diferença \\
\hline Q18. E fornecida atenção individual aos clientes? & 4,5 & 3,5 & 1,0 \\
$\begin{array}{l}\text { Q19. O funcionamento é em horários convenientes } \\
\text { para atender a necessidade de todos os seus clientes? }\end{array}$ & 5,0 & 3,0 & 2,0 \\
$\begin{array}{l}\text { Q20. Os funcionários dão atenção pessoal aos } \\
\text { clientes? }\end{array}$ & 5,3 & 3,5 & 1,8 \\
$\begin{array}{l}\text { Q21. Os funcionários têm verdadeiramente o melhor } \\
\text { interesse nos clientes? }\end{array}$ & 5,5 & 4,5 & 1,0 \\
$\begin{array}{l}\text { Q22. Os funcionários entendem as reais necessidades } \\
\text { dos clientes? }\end{array}$ & 5,0 & 6,0 & $-1,0$ \\
\hline
\end{tabular}

Fonte. Resultados originais da pesquisa

Com os dados obtidos, foi possível estabelecer a percepção média e a taxa de satisfação para as obras.

- Obra A: para a empatia a percepção média alcançou o valor de 4,68 chegando a uma taxa de satisfação de $67 \%$.

- Obra B: para a empatia a percepção média alcançou o valor de 5,06 chegando a uma taxa de satisfação de $72 \%$.

$\mathrm{Na}$ obra $\mathrm{B}$, verificou-se uma taxa de satisfação $5 \%$ maior do que a obra $\mathrm{A}$, demonstrando assim, segundo a percepção de qualidade, maior cuidado e atenção individualizada fornecida aos seus clientes. Com o resultado encontrado na dimensão empatia para a percepção de qualidade do cliente da obra B, conseguiu-se demonstrar um maior conhecimento e cortesia dos funcionários e capacidade deles transmitirem confiança e segurança. Com esta análise combinada verificou-se o motivo do resultado alcançado na dimensão garantia apresentada no item anterior.

\subsection{Distribuição de pesos para as dimensões da qualidade}

Seguindo o modelo Servqual, durante as entrevistas com os clientes da construtora foi verificada a distribuição dos pesos para cada dimensão da escala. Foi considerada a dimensão confiabilidade como a mais relevante, com 35 pontos. A 
dimensão tangibilidade foi considerada a menos prioritária. Os pesos atribuídos pelos entrevistados da obra estão apresentados na Tabela 11.

Tabela 11. Distribuição do peso das dimensões da qualidade para obra A

\begin{tabular}{lcc}
\hline Dimensões da qualidade & Aspectos & Pesos \\
\hline $\begin{array}{l}\text { A aparência das instalações físicas, equipamentos, pessoal e } \\
\text { materiais de comunicação. }\end{array}$ & Tangibilidade & 9 \\
$\begin{array}{l}\text { A capacidade do fornecedor de realizar o serviço prometido de } \\
\text { modo confiável e exato. }\end{array}$ & Confiabilidade & 35 \\
$\begin{array}{l}\text { A disposição do fornecedor para ajudar os clientes e entregar o } \\
\text { serviço no prazo. }\end{array}$ & Resposta & 25 \\
$\begin{array}{l}\text { O conhecimento e cortesia dos funcionários e sua capacidade de } \\
\text { transmitir confiança. }\end{array}$ & Garantia & 20 \\
O cuidado e atenção individualizada entregue aos clientes. & Empatia & 11 \\
\hline
\end{tabular}

\section{Fonte. Resultados originais da pesquisa}

O mesmo procedimento foi também aplicado aos entrevistados da obra B, cujo resultado apresentou a dimensão resposta como a mais relevante. Os resultados estão apresentados na Tabela 12.

Tabela 12. Distribuição do peso das dimensões da qualidade para obra B

\begin{tabular}{lcc}
\hline Dimensões da qualidade & Aspectos & Pesos \\
\hline $\begin{array}{l}\text { A aparência das instalações físicas, equipamentos, pessoal e } \\
\text { materiais de comunicação. }\end{array}$ & Tangibilidade & 7 \\
$\begin{array}{l}\text { A capacidade do fornecedor de realizar o serviço prometido de } \\
\text { modo confiável e exato. }\end{array}$ & Confiabilidade & 25 \\
$\begin{array}{l}\text { A disposição do fornecedor para ajudar os clientes e entregar o } \\
\text { serviço no prazo. }\end{array}$ & Resposta & 40 \\
$\begin{array}{l}\text { O conhecimento e cortesia dos funcionários e sua capacidade de } \\
\text { transmitir confiança. }\end{array}$ & Garantia & 15 \\
\begin{tabular}{l} 
O cuidado e atenção individualizada entregue aos clientes. \\
\hline
\end{tabular} & Empatia & 13 \\
\hline
\end{tabular}

Fonte. Resultados originais da pesquisa

Para aplicar os pesos de cada dimensão indicada pelos clientes como mais ou menos importantes, foram reunidos os resultados de todas as taxas de satisfação na Tabela 13. Nesta Tabela foram identificadas as cinco dimensões da qualidade e os resultados para as obras calculados anteriormente.

Tabela 13. Taxa de satisfação obras A e B e valor ponderado pelos pesos

\begin{tabular}{lrrrr}
\hline Dimensões da qualidade & Obra A & Peso & Obra B & Peso \\
\hline Tangibilidade & $73 \%$ & 9 & $54 \%$ & 7 \\
Confiabilidade & $84 \%$ & 35 & $49 \%$ & 25 \\
Resposta & $76 \%$ & 25 & $59 \%$ & 40 \\
Garantia & $66 \%$ & 20 & $69 \%$ & 15 \\
Empatia & $67 \%$ & 11 & $72 \%$ & 13 \\
\hline Ponderação & 75,54 & & 59,34 & \\
\hline
\end{tabular}

Fonte. Resultados originais da pesquisa

Conforme apresentado na Tabela 13, é possível realizar a seguinte análise:

- Obra A: a dimensão com maior peso, confiabilidade (35 pontos), alcançou a maior taxa de satisfação com 84\%. Já a dimensão com menor peso, 
tangibilidade (9 pontos), alcançou uma taxa de satisfação de $73 \%$, não sendo a menor taxa de satisfação, que para a obra A foi a dimensão garantia com $66 \%$.

- Obra B: a dimensão com maior peso, resposta (40 pontos), alcançou a taxa de satisfação de $59 \%$, não sendo a maior taxa, que para a obra B foi a empatia, com $72 \%$. Já a dimensão com menor peso, aspectos tangíveis (7 pontos), alcançou uma taxa de satisfação de $54 \%$, não sendo a menor taxa de satisfação, que para a obra B foi a confiabilidade com $49 \%$.

Com estes resultados, para alcançar os pontos nos quais a qualidade deve ser melhorada para as duas obras, foi aplicada a análise combinada utilizando os pesos atribuídos para cada dimensão da qualidade e as diferenças médias, conforme o método Servqual. Os resultados estão apresentados na Tabela 14.

Tabela 14. Média da diferença ponderada nas obras A e B, considerando as avaliações a cada questão e os pesos das dimensões

\begin{tabular}{lrrrrr}
\hline Dimensões da qualidade & Questão & $\begin{array}{c}\text { Diferença } \\
\text { ponderada } \\
\text { Obra A }\end{array}$ & $\begin{array}{c}\text { Média } \\
\text { Obra A }\end{array}$ & $\begin{array}{c}\text { Diferença } \\
\text { ponderada } \\
\text { Obra B }\end{array}$ & $\begin{array}{c}\text { Média } \\
\text { Obra B }\end{array}$ \\
\hline Aspectos Tangíveis & Q1 & $-18,00$ & $-5,18$ & $-2,10$ & $-3,15$ \\
& Q2 & $-4,50$ & & $-17,50$ & \\
Q3 & 4,50 & & $-3,50$ & \\
Confiabilidade & Q4 & $-2,70$ & & 10,50 & \\
& Q5 & 28,00 & 21,00 & $-50,00$ & $-57,40$ \\
& Q6 & 42,00 & & $-37,50$ & \\
Q7 & 24,50 & & $-62,50$ & \\
Resposta & Q8 & $-17,50$ & & $-100,00$ & \\
& Q9 & 28,00 & & $-37,50$ & \\
& Q10 & 12,50 & 16,88 & $-32,00$ & $-43,00$ \\
Garantia & Q11 & 5,00 & & $-60,00$ & \\
& Q12 & 37,50 & & $-20,00$ & \\
& Q13 & 12,50 & & $-60,00$ & \\
& Q14 & $-6,00$ & 5,50 & 12,00 & 6,75 \\
Empatia & Q15 & $-24,00$ & & 13,50 & \\
& Q16 & 22,00 & & 9,00 & \\
& Q17 & 30,00 & & $-7,50$ & \\
& Q18 & 6,60 & $-1,76$ & 13,00 & 12,48 \\
& Q19 & 3,30 & & 26,00 & \\
& Q20 & 13,20 & & 23,40 & \\
& Q21 & $-15,40$ & & 13,00 & \\
& Q22 & $-16,50$ & & $-13,00$ & \\
\hline
\end{tabular}

Fonte. Resultados originais da pesquisa

Para a obra A, os resultados das médias ponderadas positivas em três dimensões demonstraram valores que atingiram e superaram as expectativas dos clientes entrevistados para confiabilidade, resposta e garantia. Foram alcançados dois resultados negativos, para os quais a percepção dos clientes entrevistados foi menor do que a expectativa, não atingindo o esperado.

Foi possível observar que o ponto fraco está na dimensão aspectos tangíveis, em que se verificou a maior diferença ponderada negativa de 5,18 , sendo evidente que 
ações devem ser dirigidas ao critério da Q1, referente aos equipamentos e ferramentas de visual moderno, devido a ser a maior diferença ponderada negativa dentro desta dimensão, ou seja, 18,00.

Aspecto tangibilidade é tudo aquilo que se pode perceber por meio dos sentidos, tendo relação com a aparência das instalações físicas, equipamentos, pessoal e materiais de comunicação (BERRY; PARASURAMAN, 1995). Com esta definição, vale mencionar que esta dimensão pode melhorar a percepção de qualidade e atingir a expectativa dos clientes com um cuidado maior com todos os aspectos visuais da obra.

Para a obra $\mathrm{B}$, foram verificados os resultados das médias ponderadas positivas em duas dimensões, em que foram demonstrados valores que atingiram e superaram a expectativa dos clientes para as dimensões garantia e empatia. Foram alcançados três resultados negativos para os quais a percepção do cliente foi menor do que a expectativa. O ponto fraco está na dimensão confiabilidade, que se verificou a maior diferença ponderada negativa de 57,50, sendo evidente que ações devem ser dirigidas ao critério da Q8 referente a se foram realizados os serviços no prazo acertado, devido a ser a maior diferença ponderada negativa dentro desta dimensão $(100,00)$.

A confiabilidade, conforme Berry e Parasuraman (1995), é a capacidade de executar o serviço prometido de forma confiável e com precisão. O principal fator necessário de melhoria foi relacionado a se foram realizados os serviços no prazo acertado demonstrando uma percepção abaixo da expectativa para a obra B.

\subsection{Tempo e custo das obras A e B}

Feitas as análises pela perspectiva dos clientes, são apresentados dados reais dos dois projetos, obtidos junto ao empreendedor dos projetos. São avaliados o tempo (cronograma) das obras e seu custo. Com relação ao cronograma, a Figura 2 apresenta a evolução da Obra A.

$\mathrm{Na}$ Figura 2 é apresentado o resultado do cronograma de avanço físico no tempo para a obra A, em que se verifica que a entrega de $100 \%$ dos trabalhos, porcentagem real, ocorreu com antecedência de 13 dias (30/06) em comparação com a data de entrega prevista (13/07). Isto demonstra que foi possível executar o cronograma inicial e adiantar os trabalhos com o planejamento adequado e estudos para retomada e avanço das metas previstas no início do projeto.

$\mathrm{Na}$ Figura 3 foi demonstrado o resultado do cronograma de avanço físico no tempo para a obra B em que se verifica que a data de entrega de $100 \%$ dos trabalhos prevista foi ultrapassada e a entrega do projeto foi feita com 60 dias de atraso (finalização prevista em 31/05 e efetivada em 31/07). 
Figura 2. Avanço cronograma obra A

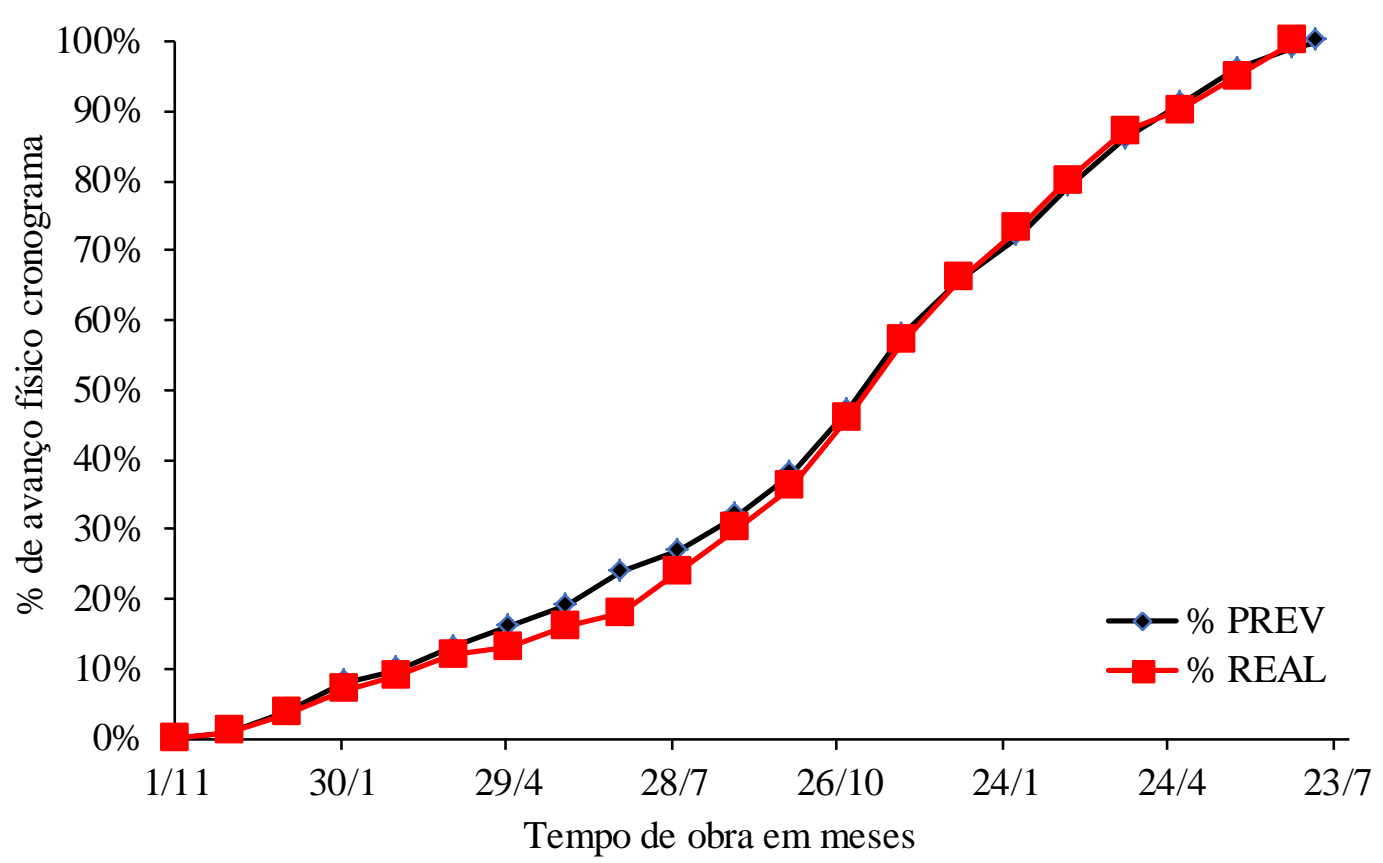

Fonte. Dados fornecidos pelo gerente de projeto da obra

Figura 3. Avanço cronograma obra B

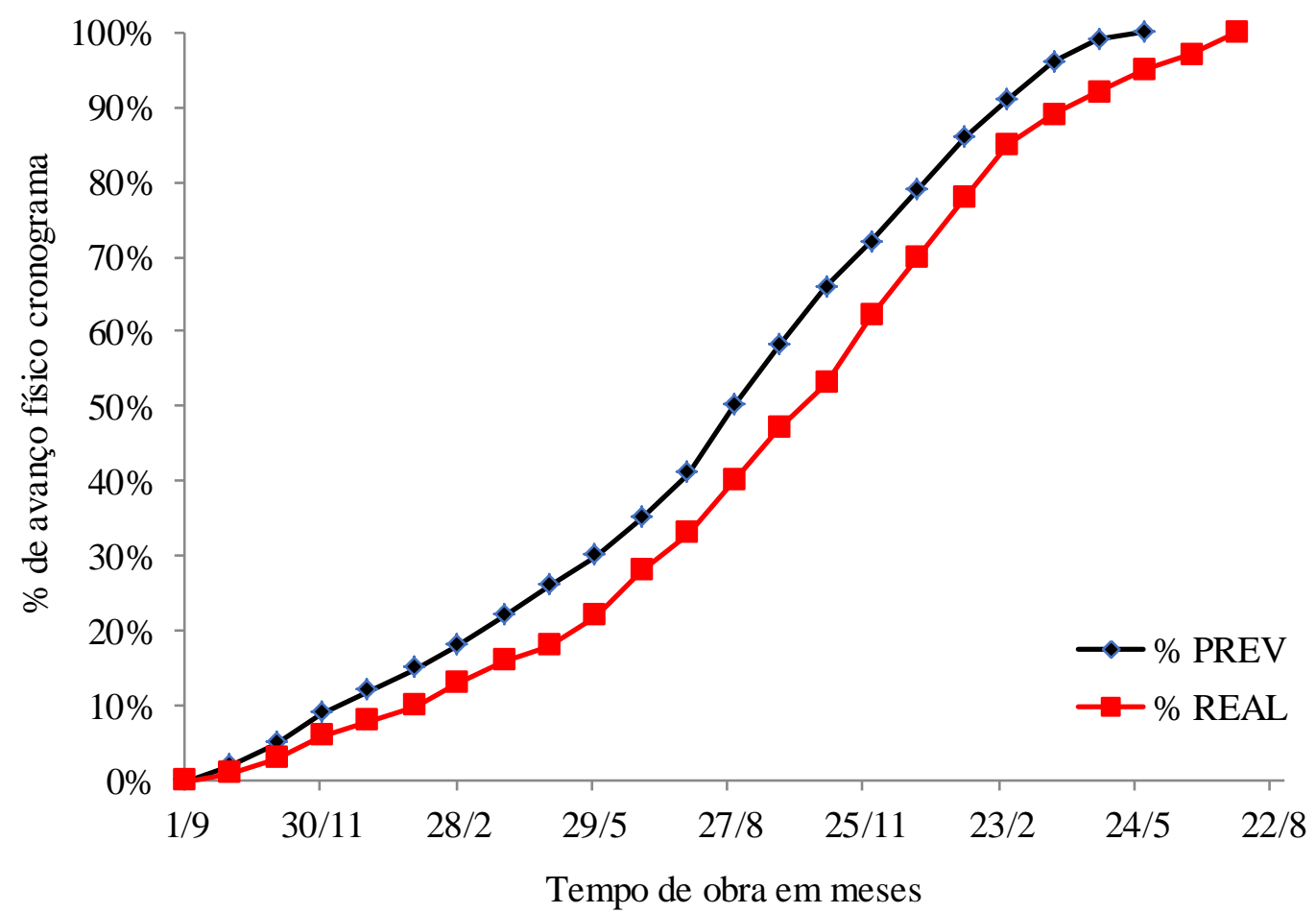

Fonte. Dados fornecidos pelo gerente de projeto da obra

Com relação aos custos, na Figura 4 são apresentados os custos previstos e efetivos por trimestre para a Obra A. É possível identificar um equilibrio no volume de 
capital gasto de acordo com o previsto para cada mês de projeto. Durante o terceiro e o quarto trimestre foi necessário um gasto pouco maior que o previsto, em torno de $2 \%$, que segundo o gerente de projeto responsável pela obra, foi compensado nos trimestres subsequentes, com gastos inferiores. Ao final do projeto, as estimativas de custos permaneceram conforme a previsão inicial.

Figura 4. Valores gastos da obra A

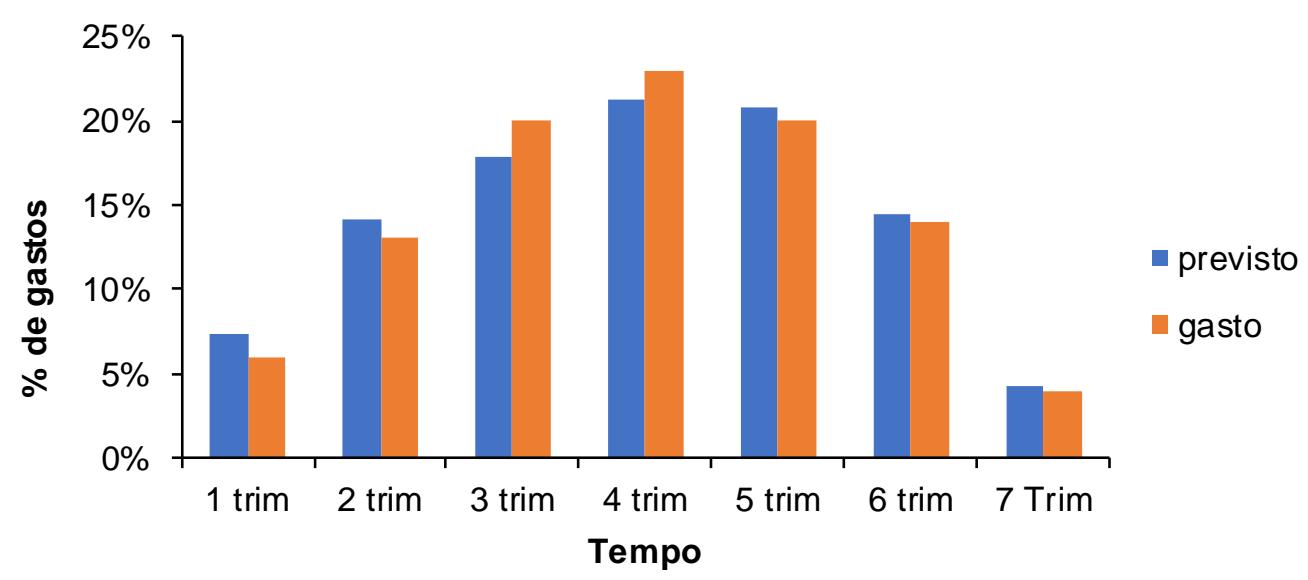

Fonte. Dados fornecidos pelo gerente de projeto da obra

A Figura 5 apresenta os valores previstos e gastos em porcentagem para a obra B. Segundo o gerente deste projeto, é possível verificar que nos três primeiros trimestres de execução do projeto foram gastos valores abaixo do previsto, em média 2,5\%. Segundo o gerente do projeto, isso ocorreu devido ao atraso identificado no cronograma de obra, apresentado na Figura 3. Após o quarto trimestre foi necessário o aumento dos gastos, passando os limites dos valores previstos para compensar o atraso causado no início do projeto. Devido à falha na entrega final, foi necessário gastos além do previsto para minimizar o impacto causado pela baixa produção inicial e manter o canteiro de obras com funcionários por um período maior, causando assim um aumento de 0,5\% no custo previsto no planejamento inicial.

Figura 5. Valores gastos obra B

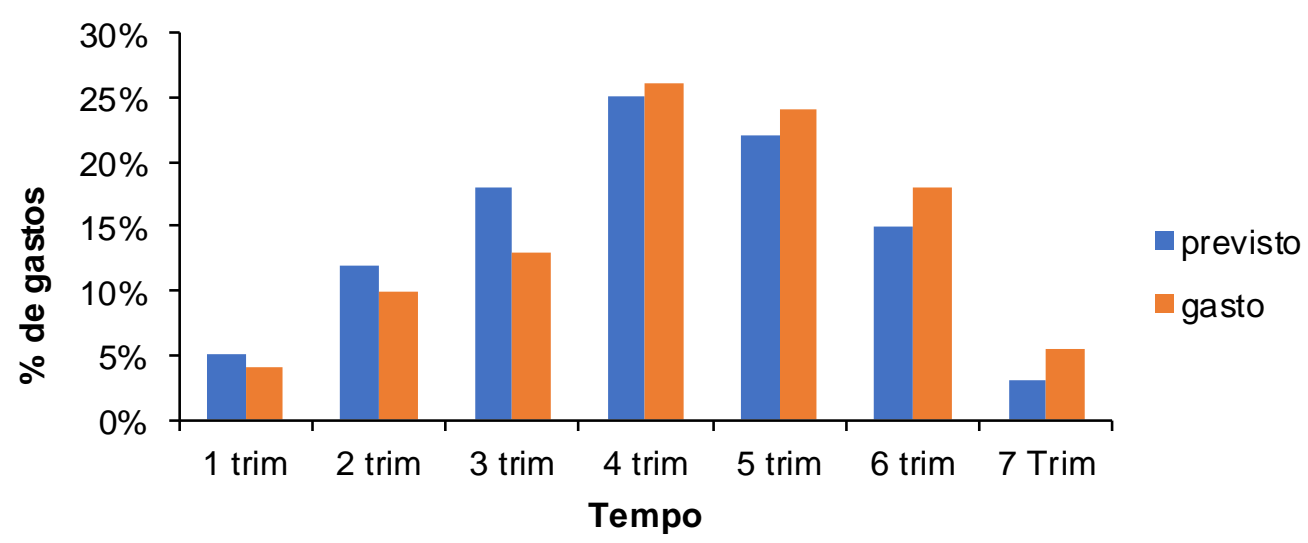

Fonte. Dados fornecidos pelo gerente de projeto da obra 


\section{Considerações finais}

A pesquisa possibilitou identificar uma diferença na percepção de qualidade demonstrada pelo cliente da obra $\mathrm{A}$, em que foram utilizadas ferramentas de monitoramento e controle, para a obra $\mathrm{B}$, em que estas ferramentas não foram utilizadas.

$\mathrm{Na}$ perspectiva dos clientes, na obra A foi identificada maior percepção de qualidade atendendo às expectativas dos clientes nos quesitos confiabilidade e resposta quando comparada com a obra $\mathrm{B}$, que teve melhores resultados nos quesitos garantia e empatia. A obtenção de maior percepção de qualidade nos quesitos confiabilidade e resposta pela obra A demonstra maior capacidade de executar o serviço prometido de forma confiável e precisa e disposição para prestar um serviço rápido, influenciando diretamente nos resultados de tempo para entrega do projeto. A influência exercida no tempo de entrega normalmente é acompanhada por alterações no custo da obra.

Avaliando na perspectiva da construtora, que se preocupa prioritariamente com as dimensões do triângulo de ferro, a pesquisa identificou que para a obra A, 100\% dos trabalhos foram entregues dentro do prazo estipulado, com adiantamento de 13 dias e o custo foi mantido dentro do previsto. Já a obra $\mathrm{B}$ não conseguiu manter o prazo previsto, tendo um atraso de 60 dias e estourando o custo em $0,5 \%$. Com relação à qualidade, a construtora entendeu que atingiu os objetivos, uma vez que ambas foram aceitas pelos clientes.

Embora os resultados encontrados demonstrem que a percepção de qualidade das obras aumenta em alguns quesitos importantes quando há a utilização de ferramentas de monitoramento e controle, não é possível concluir que há a influência direta na percepção final do cliente. Em função da vasta gama de variáveis que podem influenciar a entrega, o custo e a qualidade de uma obra de Engenharia Civil, não é possível atingir esta conclusão. Portanto, não existe a garantia de sucesso, o que se pode concluir é que a percepção de qualidade do entregável melhora para o cliente com o uso destas ferramentas.

Esta pesquisa se limitou a realizar o comparativo entre duas obras de porte similar com área de até $5.000 \mathrm{~m}^{2}$ realizadas por uma única construtora. Apesar de similares, não foram analisadas possíveis características peculiares de cada um destes projetos. Em estudos futuros seria de grande valia aumentar o número de obras comparadas para que os resultados possam ser estudados em conjunto com os obtidos nesta pesquisa. Com o incremento de entrevistados e amostras, sugere-se também que sejam empregados de métodos estatísticos mais robustos, como análise multivariada e paramétrica, com a formulação de hipóteses.

\section{Referências}

ATKINSON, R. Project management: cost, time and quality, two best guesses and a phenomenon, its time to accept other success criteria. International Journal of Project Management, v. 17, n. 6, p. 337-342, 1999.

AZEVEDO, R. C.; ENSSLIN, L.; LACERDA, R. T. D. O.; FRANÇA, L. A., GONZALEZ, C. J. I.; JUNGLES, A. E.; ENSSLIN, S. R.. Avaliação de desempenho do processo de orçamento: estudo de caso em uma obra de construção civil. Ambiente Construído, v. 11, n. 1, p. 85-104, 2011.

BATEMAN, T. S.; SNELL, S. A.; RIMOLI, C. A. Administração: construindo vantagem competitiva. 1998. 
BERRY, L.; PARASURAMAN, A Serviços de Marketing-competindo através da qualidade. Editora Maltese. São Paulo, p. 11-24, 1995.

BORGES, J. F. B. Gestão de Projetos na Construção Civil. Especialize, v. 01, n. 5, p. 01-16, 2013.

CARVAlHO, M. M.; RABECHINI JR, R. Fundamentos em Gestão de Projetos (4 ed.) São Paulo: Atlas, 2015, 422 p.

CODAS, M. M. B. Gerência de projetos: uma reflexão histórica. Revista de Administração de Empresas, v. 27, n. 1, p. 33-37, 1987.

DINSMORE, P. C.; COOKE-DAVIES, Terence J. Right projects done right: from business strategy to successful project Implementation. John Wiley \& Sons, 2006.

KERZNER, H. Project management: a systems approach to planning, scheduling, and controlling. John Wiley \& Sons, 2009.

MAXIMIANO, A. C. A. Administração de projetos: como transformar ideia em resultados (4 ed.) São Paulo: Atlas, 2010.

PMI. A guide to the project management body of knowledge (PMBOK guide). Project Management Institute: Newtown Square, 2013. 